\title{
Collective Intelligence on a Robotic Project, a Pedagogical Experience in a Pre-school Garden at Nariño (Colombia)
}

\author{
Carmen Alicia Acosta ${ }^{1}$, Maria Alejandra Cabrera ${ }^{1}$, Nohora Lucía Caicedo ${ }^{1}$, \\ Paola Torres ${ }^{1}$, Yudy Andrea Hernández ${ }^{1}$, Maria Inés Medina Villarreal ${ }^{1}$ \\ Angélica María Gómez Medina ${ }^{2}$, Victor Andrés Bucheli $^{3}$ \\ ${ }^{1}$ Jardín Infantil Psicopedagógico Personitas del Mañana. Calle 9 Número 41-27. Mariluz III Pasto-Nariño, Colombia. \\ ${ }^{2}$ Universidad Manuela Beltrán. Avenida Circunvalar \#60-00 Bogotá-Colombia. \\ ${ }^{3}$ Escuela de Ingeniería de Sistemas y Computación, Facultad de Ingeniería - Universidad del Valle. Cali - Colombia.
}

\begin{abstract}
This paper presents a pedagogical experience to initiate the boys and girls in the technology world in childhood education. The pedagogical experience is based on participatory research, in which, preschool teachers and researchers proposed a didactic method to build robots in a kindergarten. Thus, boys and girls are induced to technology, investigation and research thinking. Furthermore, the meaningful learning was reached through this ludic pedagogical project related to science and technology, where they produced knowledge and technological devices. We have highlights about the relation between technology and early childhood education, in which, one education challenge is to design didactic methods where expert and non-expert knowledge lead to a collective intelligence in class; while teachers play many roles, and preserved the ethic citizens values. We implemented a ludic pedagogical project for collective production of technology (robots). It took place in an institution of early preschool education, at Jardin Infantil "Personitas del Mañana" in Pasto Nariño, Colombia.
\end{abstract}

Index Terms - Collective intelligence, pedagogical experience and robotic project in early childhood education

\section{Introduction}

On the basis of ethnographical matters and critical auto reflections, we developed this paper. Furthermore, the question of traditional pedagogical practices, taking place in the garden and its pertinence for the preschool education: Are ours traditional daily pedagogical practices driven by contemporary challenges, which are faced by preschool boys and girls?.

Within this framework we have found more specifically questions which can out the different agents of this research. They are referred to the daily technologies which children find in their living environment. We ask ourselves for ethical correspondence, the role of school to face the challenges of current society and to accompany both preschool girls and boys to empower them in early education.

In this way the problem rises for the pertinence and technology known in children from early childhood. How technology is incorporated to education and which role does it have? In which way does the collective knowledge production help to solve technology challenges? How does rise the challenge solutions from the collective: boys and girls children, teachers, experts within the garden? How do each one of them face technology? How can be tackled gender in empowering boys and girls in technology? How to design didactically materials for a positive approaching to technology? How should the ethical and political highlights be included in a robotics project?

\section{Teoretical Framework}

According to Pérez Bustos (2013) technology access is relevant in so far as it concerns different players and agents both experts and lays [13-14]) for powering democratization in knowledge production. In this way this work is done within collective knowledge contraction [15]. This view gives rise to a stress in so far as we think it must answer global challenges tackled from local level. We adopt a critical education paradigm concerning scientific knowledge production from the market logic. So regarded if technology is a challenge it should be faced also as an ethical and political bid within which we incorporate our pedagogical practice in order to build a more just and including world [15]. So viewed robotics trespass the strict borne of a cold expert practice to become a collective building of knowledge taking place inside the children classroom from the early childhood. In this way, technology use from early infancy becomes a pertinent practice in looking for knowledge, a meaningful learning $[2,3,4,5,6]$ and a daily doing for caring.

Therefore activities underpinning pedagogical daily practice in the garden choose for building up a technology knowledge linking citizenship education together with environment care and gender education. Hence technology as a contemporary global challenge is regarded from our ethical standing as a daily doing with needed and unavoidable technology tools intersecting all reality including own corporeality [12]. In this way, as a tool, technology offers potentials for developing many dimensions. Then, since our view looks for knowledge production that is pertinent for living, we ask teachers should become a mediator role in children thinking, as agents for learning, empowering for innovation and generating own technological productions. That said it should be assumed an ethical view for a fair and including world.

The need of this coherence between science and ethical political views made us inscribed in which Perez Bustos (2013) named a "careful doing strategies". For this author caring means as well we acknowledge vulnerability and, therefore, mutual dependency. So doing, it is implied caring suppose many practices for being touched and concerned by 
another people wellbeing, from which are woven networks showing and triggering relative autonomies (Sevenhuidjsen 2003, quoted by [13]). Besides, caring asks collective feelings, affective bonds creation and solidarity relationships. Knowledge transmission goes beyond mere information transmission up to a bid to creating human links. Scientists and experts are then asked to make arise transformation processes in jointly working with another society members such as teachers and educators [14].

On these coordinates we can build up together with experts and lays knowledge a ludic pedagogical proposal allowing us to build up technology from our three transversal axis: sexual education with gender perspective, environmental friendly education and citizenship education.

\section{How Our Experience Unfolded}

First of all, it was needed to tackle the question in a collective frame which arise curiosity for enabling a creative thought development of children. For starting it supposes to accept the ideas that children and pedagogical team keep of robotics.

For so doing, we have to accept a standing as mediators of the pedagogical team which allows a watching pedagogy triggering conflicts in knowing and also questioning deepening the given knowledge. Questions such as: what is it a robot? How do they imagine it? What stuff is needed to build it up? What is good for? How does it work? How does it to make moves on? How does it walk? Where can we find them nowadays? What do you think a robot either man or woman is not able to do today? How can we identify a robot -whether boy or girl-within its surroundings? How can we build it?

How does choose a robot what should do? What do we make a robot for? Are needed robots in our daily livings? What do we use technology for? How do I imagine my own robot -whether boy or girl? In this point we perceive an increasing interest of children -girls and boys- for technology. Interest astonishment and curiosity are all needed tools for stimulating creative thinking, for team working and problem solving and also looking for meaningful learning [2-3][5-6]. Then we stand up in a view of early education that sees emotional dimension a building block of daily pedagogical doing.

Therein it is possible to design a free graphical representation of what we imagine and we will as a robot whether it is wanted as boy or girl-. In this way possibility is opened so that we can explore arts and involve them upon the new project to generate a new knowledge. "Children boys and girls describe them as two toys in one: a robot at which by making some reshuffling and changing some chips can be transformed into auto motor, aircraft or animal among other things". It has to be taken into account willing according the specifically social context of children and diversity of cultural capital accumulated by each of them for asking: how would they liked should be the transformer? Once identified previous knowledge derived from their socialisation process follow up hypothesis formulations and collective questioning for building up robots.

First phase: Project first stage opens questioning. Adressing question is: what is a robot? Children boys and girls were invited to design graphically their ideas and express them and write them down in their own writing system.

Children ideas were brought up a forwarded and socialized way with their own pre-schoolmates. Ideas put forward were such as:

"A robot is an assistant and it does home jobs".

"It is a puppet which moves around home and it does things and is very strong".

"My woman robot is a Mistress who has got a family and cares for them" and loves them".

"Robots walk by means of powered strings and are very clever".

"Women robots can walk and make paintings by hands and can make twisting hairs and weep out".

Together with systematization of various ideas of children about robot(ic)s we can say that prevails the idea of robot as a metallic human like body. Besides it is obvious media influence on contextual globalization of specific business interests. Again, it arises the thought and question on the chance of using these resources as children tools as world citizens themselves. In addition, we can observe that most children catch robot idea and of any way they have been astounded by the question: what is a robot- whether boyish or girlish like- In this ideas storm braining is noticeable that of womanlike robot invested by motherhood qualities and doing home jobs. Generally, boys designed graphically boyish like robots and girl's girlish like robots. How do I imagine my boyish or girlish-like robot? After discussing robots ideas in an overall meeting they drawn their imagined robot and written its characteristics down in their own childish writing system.

In theirs draws are noticeable theirs ecological and environmental values and wishes to undertaking robot tasks and movements. Besides they make mention to several working mechanisms. Then recyclable stuff brought from homes was reclassified, sticks and trademarks symbols were tagged. Across the football sport field of garden did take place an exploration and selection of qualities of wild materials of environmental surroundings and were described possibilities of production using them and were designed freely several schemes for building up boyish and girlish like robots by children.

Through this activity preschool children of both sexes have shown great creativity thought, strengthened collective working, and they worked in problem solving, respecting another children views, reached agreements and identified recycled stuff from home and garden.

Second phase Show of "little Roberta": Little Roberta a girlish like robot built by teachers was showed, see Fig 1.; she was carefully looked at and Amusing activities were carried out with allowing the students to explore its moves and sounds.

As result of the numerous interactions with the students, some questions were brought up like "what do you imagine 
Little Roberta can do?"; "what kind of materials were use to build it?"; "How do you think it work? and so forth

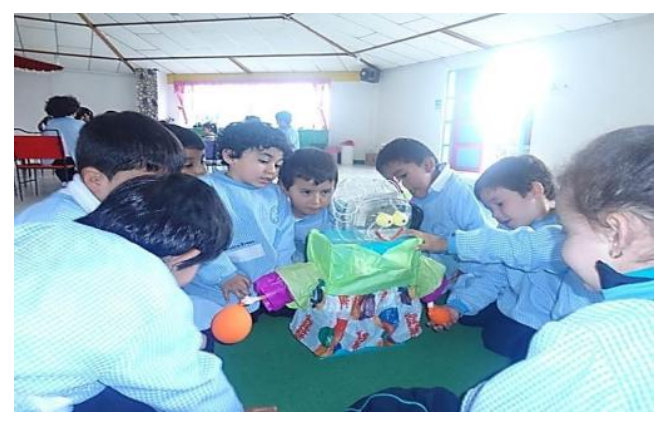

Fig. 1 Exploring Robertina.

Hypothesis, appreciations, ideas: "Little Roberta works powered by battery", "If light is off little Roberta does not work because there is not electricity power", "Little Roberta works by pushing on and off a key", "Little Roberta head has memory which endows her of cleverness and movements and allows her to make horn sounds", "it bears many wires", "there are greenish, yellowish, dark pinkish, little boxes, bound together with adhesive tape", "when you turn it on a red key is lighted", "little Roberta has got inside her body a battery which gives it power", "the colored boxes have gotten inside wires which allows it to do sounds and movements", "I think the green box is that gives it sound", "the yellowish box goes along arms causing them to move", "the eyes light on and off since wires either are plugged or unplugged", "little Roberta is a girlish like robot since she can do many things", "we would like little Roberta was able to walk".

The natural kind of observation and curiousness of children push them to explore and look for new discoveries. They follow up the wires way and then they see these are going on to arms whose movements up and down they suppose are powered by them. Similarly some wires are going to robots eyes which so can be lit on and off. Besides, all wires are finally connected to batteries which gives the power for making it works. By exploring different parts of a robot and observing different outcomes easily find the cause of them in an unending research of scientific thought development. These questions became our starting point for building up our own boyish and girlish like robots. Taking into account that scientific education experience starts upon children questions, theory insights, their own interpretations of world observations, their interests and own motivations. It was so as the first knowledge of children of both sexes were the beginning of this research process.

Involving children boys and girls of preschool age in this research of questioning communities evidences targets attainments and the changement of mental children structures. In this way they have gone beyond anthropomorphic conceptions of programmed machines and understood there are new possibilities ' of create forms other than human beings. Then they have seen possibilities for building up of girlish like robots, surpassing androcentric conceptions in technology making and accessing a field with traditional masculine predominance.

In addition it was devised a wall panel showing most relevant qualities of robots, children's preliminary ideas, appreciations, likings, interests and motivations. Besides in it was determined basic functions and movements, see Fig. 2.
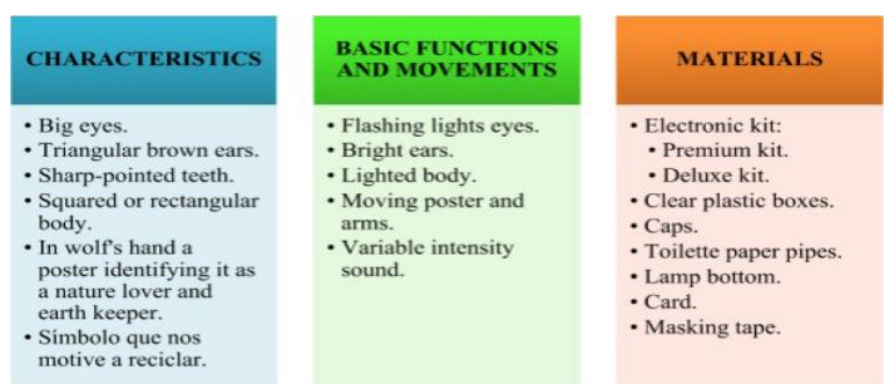

Fig. 2 children's preliminary ideas, appreciations.

Third phase Collective making up of wolf robot: The recyclable stuff which children brought from homes were classified and it was chosen that best suited to build up our wolf robot.

First steps handling on kits allow us to design and to make a prototype of wolf robot. Thorough observation, exploration, handling, experimentation were reached important discoveries.

The difference modules which made up the Kit Little Bits electronic base kit: fans, buzzers, exits, sensors, sequencers, extensors, $9 \mathrm{~V}$ batteries. It was found all they have magnet which allow to make connections of little modules and devising electronic gadgets which turn them interesting. Besides, magnets prevent couple mistakes. In addition, it was acknowledged each magnet characteristic such as light, sound, motor. These allow playing with light, sound, moving, sensors, sequencers, keys without needing of wires, solder, programs. By try and error were identified the module should be used for doing every function by robot. From other angle it could be concluded importance of charged batteries for the reciprocal working of different modules.

During this process thought abilities were spoilt such as: effect and causation by experiments with electronic kits and by making robots of lighted eyes and ears, arms movements, sounds with sequential pattern of intensity and moving tail [78]. During these working journeys the task of teacher is mediating to integrate by the building of wolf and dog robots different areas of knowledge and different dimensions of thought such as: mathematics [7-8], electronics, mechanics, arts [10]. In this way activity is articulated as ludic choices in different areas of knowledge production and technology becomes a tool for empowering several features of creative thought [2-5]. We inscribed ourselves in a perpetual seeking of questions arisen of daily doing into classroom.

Four phase - A little Spiderlike robot: A spiderlike robot hanging under the ceiling as a decorative chip did arise many questions of preschool children in both boys and girls. Thisdaily event may be understood as a problematical situation 
[9] within pedagogy, and it did become a pretext to mediating of teachers and to starting a collective enquiry on spiders articulating knowledge with robotics project, see Fig. 3.

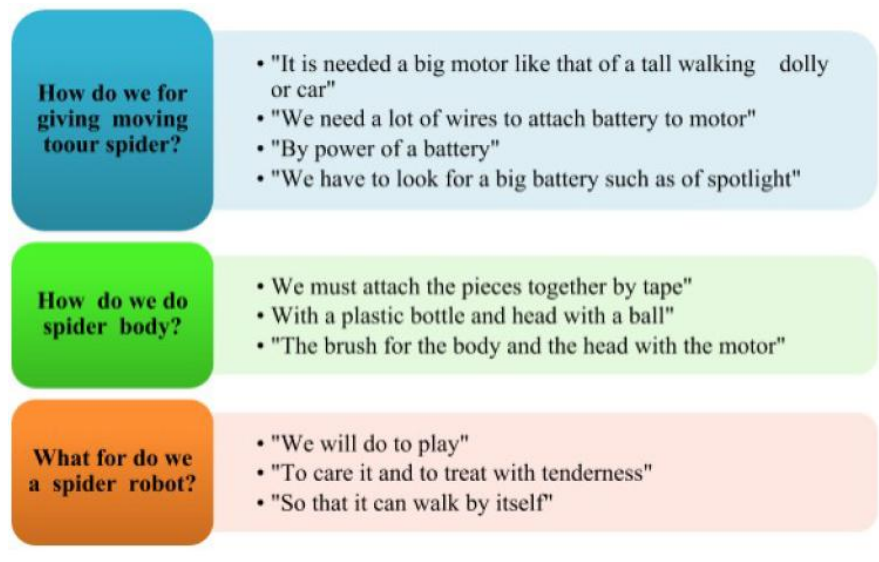

Fig. 3 Spider robot

The intrinsic motivation of boys and girls in preschool children in collective building of a bug robot allowed also to articulate it with classroom taught subjects. In this way, the group started working eight pieces in relationship to number 8 and associating this number with spider eight legs [8].

Executing stage: On this stage of making of a spiderlike robot it took place an experiment with the stuff and pieces for building it. This translates in experimenting with materials trying to design individually the spider. This gives place to spoil creative and artistic thought by means of a free deign of spiders, which makes possible singular expression of children. Then on it took place a journey of experimenting activities for handling and operation of electronic materials in order to build up robot mechanical part with female teachers involvement to achieve the spider robot assembly. It was addressed with questions which allowed a transition to a higher level of complex thought. The project was made known to all with children as main actors and actresses of our community, making a rupture about the pertinence and possibility of technology access from early childhood.

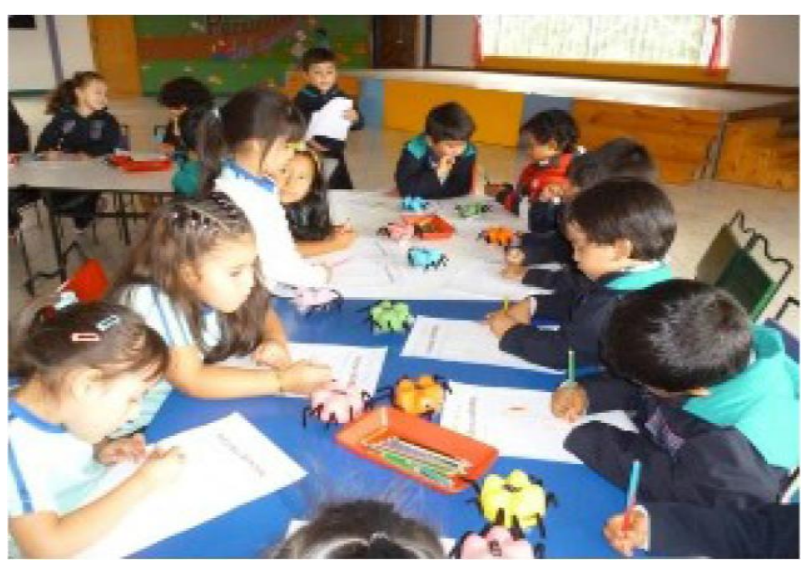

Fig. 4 Stage of making of a spiderlike robot

\section{Conclusion}

This communication aimed at answering the questions about the pertinence and possibility of technology use and access from the early childhood. This was framed within a wider question about pertinence of traditional pedagogical practice pertinence in face of contemporary challenges faced by children of preschool age in our nowadays world. As a collective work made jointly by knowhow of experts and lays, robotics experience as an enquiry community allows us to tell that technology access is a contemporary challenge. Education task is making of it a democratic tool which allows us made possible a collective education to achieve with the main proposal of it i. e. a more inclusive and fair world. The accomplished experience in the Preschool Garden let us state that robotics subjects can be tackled from early education. Also it is possible through a thought support let us follow a "careful daily doing" which spoils development of creative scientific and Artistic thought of all teachers and children in both genders, inscribed within a new paradigm in which the technological knowledge is not only in hands of experts but also in those of all and there is possible to access to it from early education.

\section{References}

[1] Ander Egg, Ezequiel (2003) Repensando la Investigación Acción participativa. Grupo editorial Lumen Hvmanitas. Colección Política, Servicios y Trabajo Social.

[2] Ausubel, D. (1963). The Psychology of Meaningful Verbal Learning. New York: Grune \& Stratton.

[3] Ausubel, D.P. (1968). Educational Psychology: A Cognitive View. New York: Holt, Rinehart \& Winston.

[4] Ausubel, D.P., Robinson, F.G. (1969). School Learning: An Introduction To Educational Psychology. New York: Holt, Rinehart \& Winston.

[5] Ausubel, D. (1978). In defense of advance organizers: A reply to the critics. Review of Educational Research, 48, 251-257.

[6] Ausubel, D., Novak, J., \& Hanesian, H. (1978). Educational Psychology: A Cognitive View (2nd Ed.). New York: Holt, Rinehart \& Winston

[7] D'Amore B. (2000). La escolarización del saber y de las relaciones: los efectos sobre el aprendizaje de las matemáticas. Relime. 3, 3, 2000, 321-338.

[8] D’Amore B. (2006). Didáctica de la Matemática. Bogotá: Editorial Magisterio.

[9] Bravo Salinas, Néstor H., (1997) Pedagogía Problémica: Acerca de los nuevos paradigmas en educación, Bogotá, Convenio Andrés Bello, 184 p.

[10] Gardner, H. (1993). Arte Mente y Cerebro. Paidós: Barcelona.

[11] Haraway (1991). A Cyborg Manifiesto: Science, Technology and Socialist. Feminism in The Late Twentieth Century. In Simians, Cyborgs and Women: Reinvention of Nature (Routledge). New York, p. 149-81.

[12] Perez Bustos T. \& Botero Marulanda D (2014). Otras Practicas.

[13] Educomunicativas, Otras Sexualidades, Potencialmente otro Ethos Cientifico. En Revista de Estudios Sociales 49: 113-127.

[14] Perez Bustos T. (2014). Of Caring Practices in new media Science Communication: seeing through trans-women scientists' experiences. Signs 39(4): 857-866

[15] Pierre, L. E. V. Y. (1997). Collective Intelligence: Mankinds Emerging World in Cyberspace. Cambrigde, Mass.: Perseus Books. 